\title{
DO GEOGRAPHIC FACTORS PREDICT EMERGENCY PREGNANCY OUTCOMES?
}

\author{
Nugroho Susanto \\ Universitas Respati Yogyakarta
}

\begin{abstract}
Background: Maternal and infant deaths are global public health problem. It was hypothesized that the location and socioeconomic status may contribute to health outcomes. A high and sloping location may be associated with emergency pregnancy outcomes such as bleeding and eclampsia. This study aimed to determine the association between maternal characteristics, geographic factors, and the risk of emergency pregnancy outcomes.

Subjects and Method: This was an analytic observational study with a crosssectional design conducted in Bantul, Yogyakarta. A sample of 612 pregnant mothers consisting of 306 pregnant mothers who lived in the rural area and 306 pregnant mothers who lived in the urban area was selected for this study. The dependent variables were bleeding and eclampsia. The independent variables were age, parity, history of abortion, history of Cesarean section (SC), altitude, and inclination. The data of bleeding and eclampsia were collected from the medical record. The altitude and inclination data were measured by Garmint 3.0 tool. The ordinate points were calculated by the health mapper software program. The other variables were measured by questionnaire. The data were analyzed by logistic regression.

Results: The proportion of abortion history in rural area (10.5\%) was higher than in urban area (4.9\%). The proportion of bleeding in rural area (11.4\%) was higher than in urban area (3.6\%). The proportion of eclampsia in rural area (6.9\%) was higher than in urban area (3.3\%). The risk of bleeding increased with age $(\mathrm{OR}=1.39 ; \mathrm{p}=0.001)$, abortion history $(\mathrm{OR}=1.72 ; \mathrm{p}=0.001)$, and altitude $(\mathrm{OR}=1.14 ; \mathrm{p}=0.023)$. The risk of bleeding decreased with parity $(\mathrm{OR}=0.21 ; \mathrm{p}=$ $0.631)$, SC history $(\mathrm{OR}=0.03 ; \mathrm{p}=0.806)$, and inclination $(\mathrm{OR}=0.66 ; \mathrm{p}=0.127)$. The risk of eclampsia increased with age $(\mathrm{OR}=2.31 ; \mathrm{p}<0.001)$, abortion history $(\mathrm{OR}=1.55 ; \mathrm{p}=0.019)$, $\mathrm{SC}$ history $(\mathrm{OR}=1.52 ; \mathrm{p}=0.221)$, and inclination $(\mathrm{OR}=$ $1.01 ; \mathrm{p}=0.044)$.

Conclusion: The risk of bleeding increases with age, abortion history, and altitude, but decreases with parity and SC history, and inclination. The risk of eclampsia increases with age, abortion history, SC history, and inclination.
\end{abstract}

Keywords: bleeding, eclampsia, altitude, inclination, rural, urban

\section{Correspondence:}

Nugroho Susanto. Universitas Respati Yogyakarta. Email: gegerfetp@yahoo.com. 